\title{
Medicolegal Issues Concerning Women in India
}

\author{
Swapnil Sudhirkumar Agarwal \\ Professor, Forensic Medicine \& Toxicology, Pramukhswami Medical College \& Shri Krishna Hospital \\ Karamsad, Anand, Gujarat. \\ Corresponding Author: Swapnil Sudhirkumar Agarwal \\ E-mail: swapnilagarwal@yahoo.in
}

\begin{abstract}
With passage of time and change in culture, women have taken the centre stage by gradually moving into the workforce and getting career-oriented. However, mental, physical and sexual harassment, misogyny and gender inequality continue to be a way of life for most of them. It is in this context that her awareness of the legal rights, mandated by Indian law, gains significance. Most of us, including females are generally not aware of the provisions related to the improvement of their own position. Even if they know about some of the provisions related to their rights of succession, marriage, or family, they do not desire to invoke them.

Many of their rights are related to medical examination and treatment. Medicolegal is something that involves both medical and legal aspects. It can be a legal issue that requires medical expertise or a medical condition that requires legal discourse. The Constitution of India guarantees equality to all Indians. In addition, it allows special provisions to be made by the State in favour of women and children, renounces practice derogatory to the dignity of women, and also allows for provisions to be made by the State for securing just and humane conditions of work and for maternity relief also. The current paper highlights the existing provisions in law for women in India with regards to their rights in relation to medical services.
\end{abstract}

Keywords: Witness, consent, medical examination, fertility, abandonment, domestic violence.

\section{INTRODUCTION}

Medicolegal is something that involves both medical and legal aspects. It includes legal issues that require medical expertise or medical issues that need to be executed within existing laws. Females often encounter medial conditions that have legal ramifications too. Some of these include and are discussed in following text.

1. Medical examination and consent

2. Dowry death and its investigation

3. Postmortem examination

4. Notification of birth/ abandonment of child

5. Impotence/ Sterility/ Artificial insemination

6. Surrogacy/ Pregnancy/ Fetal Sex Selection

7. Medical termination of pregnancy

8. Alleged sexual assault 
The practice over last two decades of author shows that women are hardly aware of their rights and only try to invoke them, when things go wrong. Detail provisions related to above issues form the text of the article.

\section{MEDICOLEGAL ISSUES}

There's an unwritten rule which says that whenever a female patient is examined by a male medical practitioner, it is preferable to have a female witness by side during medical examination. This is to safe guard from later litigations of alleged sexual harassment or assault by the examinee. Best is to keep a relative of the examinee otherwise hospital nurse or even a neutral witness would do. A precaution to be observed is that signature of the witness should always be taken on case papers and informed that her being witness doesn't mean that she shall be called up in a court of law to depose, as a routine. This would make more and more neutral witness to be available during such examinations.

With respect to examination by a medical practitioner, a general rule for consent in India, which is applicable to both genders is that consent of the examinee is sufficient is he/ she is above 12 years of age - for a procedure that is not a threat to life; this indirectly means 'medical examination' [Section 87, 88, 89, 90 Indian Penal Code (IPC)] [1]. Hence, any girl has a right to refuse or go ahead with any medical examination, if she is above 12 years of age; defying any pressure from peers or guardians. If he/ she is below 12 years of age or of suffering from mental illness [of any age] consent of parent/ guardian or next of kin is mandated [Section 90 IPC] [1]. In cases of sexual assault, wherein the victim is $<12$ years and alleged perpetrator is nearest relative, consent is best taken from Magistrate or Juvenile Justice Boards [present in each district]. For procedures involving risk to life, age of consent of examinee is 18 years [Section 87 IPC] [1]. It may happen that parents of a child can themselves be below 18 years. There is no law guiding as to who shall give consent in case the child needs examination or a medical procedure. Ethically, in capacity of parents, they must be entitled to give consent for their child.

As per Indian Law, if any female, who is accused of a crime and needs a medical examination for the required case, she can be examined only by a female medical practitioner and reasonable force can be used for examination or for taking of requisite samples [Section 53 (2) Criminal Procedure Code (CrPC)] [2].

With respect to medicolegal postmortems, there are different rules governing different States in India. There is no general ban on conduct of medicolegal postmortem after sunset and before sunrise. Some States allow postmortem to be done 24 hours a day while some have come out with regulations, governing timing of postmortems. In Gujarat, in certain instances, postmortem is not allowed after sunset and before sunrise. Out of them, inclusions are - female between 20-35 years of age/ death of a female in house of in-laws/ any suspicious death of female; death from poisoning; suspected suicidal death; death following sexual assault or body in a state of decomposition. These rules need to be taken care as and when request for postmortem is received after sunset in State of Gujarat [3].

By law, no person can be touched [examined or treated] without his/ her explicit consent. Violations can be tried under Section 351 IPC and Section 350 IPC [1]. This rule would apply to National Programs too, wherein immunization programs are undertaken. If the recipient agrees to go ahead with the executed programs, consent is taken to be implied. At the same time, every person has a right to expressly deny too; which cannot be enforced by anyone. This doesn't hold good where State explicitly passes an order to do something, where consent of the person gets overridden.

Consent of both husband and wife is mandated in cases of sterilization and artificial insemination but not for medical termination of pregnancy [MTP]. For MTP, only consent of girl is needed, when done as per the provisions of Medical Termination of Pregnancy Act, 1971. Any person, boy/ girl, can refuse to undergo any examination or procedure, even though life-saving; being known as Informed Refusal.

As per Section 304 [B] IPC [1], where the death of the woman is caused by any burns or bodily injury or occurs otherwise than under normal circumstances within seven years of her marriage 
and it is shown that before her death she was subjected to cruelty or harassment by her husband or any relative of her husband for, or in connection with any demand for dowry, such death shall be called 'dowry death' and such husband or relative shall be deemed to have caused her death. In all such cases, postmortem is mandatory to be done by a panel of medical practitioners.

As per Section 317 IPC [1], intentional abandonment of child below 12 years is punishable with imprisonment of either description upto 7 years and fine. Even concealment of birth by burying/ disposing dead body of a child [born alive or dead] is punishable with imprisonment upto 2 years and fine. Apart from the discovered child, alleged mother is also examined by a medical practitioner on request from an investigating officer.

A marriage can be made 'null and void' on grounds of impotence before the marriage. This doesn't hold good for sterility. Fecundacio ab extra is a condition wherein a female gets pregnant after deposition of semen around external genitals or upper thighs, without an actual act of sexual intercourse taking place. Here also, marriage can be 'null and void' on grounds of impotence of husband even though wife is pregnant with his own child.

Since a Supreme Court Judgement in September 2018, adultery is no longer an offence in India. Earlier, it was an offence where only male was held accountable with no punishment for the female in the act.

India is still awaiting a Central Law to regulate Artificial insemination and issues thereof. Delhi Artificial Insemination [Human] Act, 1995 exists which is only applicable to State of Delhi [4]. Some of its provisions include that a donor needs to be tested for HIV antibodies before accepting semen, semen to be preserved for at least 3 months before using it, written consent of recipient wife and husband needed, one cannot segregate XX or XY chromosomes for insemination, maintenance of secrecy of recipient and donor etc.

Artificial Reproductive Technology [ART] Guidelines have been laid down by ICMR [5] which do not mention any punishment for violations of the guidelines. In case of any contravention to the guidelines, only Medical Council of India or State Medical Council can take an action depending upon the complaint. All information is to be kept confidential. Artificial Insemination Donor [AID], without husband's consent can be ground for divorce and fertility from ART does not amount to consummation of marriage [making it still a ground for voidance of marriage]. It is the doctor's duty to check that donor and recipient are not related [to be safe, include an exclusionary clause] and child born is to be considered to be legitimate. Minimum age for ART [except for infertile husband/ woman medically unable to conceive] is 20 - 30 years of woman, with 2 years of cohabitation without use of contraceptive and if woman is $>30$ years, 1 year of cohabitation without use of contraceptive. Child born out of AID to has no right to know the name of donor. In case of divorce during such pregnancy, usual laws apply; also there is yet no law that bars unmarried female to use ART to become mother.

Surrogacy has been allowed in India since 2002. Central Government was to bring a regulation since 2008 which has still not seen light of the day. Currently, The Surrogacy [Regulation] Bill 2018 [2016] [6] is held up in Parliament to be enacted into law. The proposed provision include that couple must be married for at least 5 years, either one of couple must have proven infertility, age of couple acceptable would be 23 - 50 for females and 26 - 55 for males, only Indian citizens to be offered surrogacy with exclusion of even Non Resident Indians [NRI], a woman can be surrogate only once and a married couple can only have one surrogate child, the couple should employ an "altruistic relative", i.e. the surrogate mother should be a relative who is sympathetic to the situation with ban on egg donation. Explicitly, surrogacy will not be allowed for homosexual couples, single parents, couples in live-in relationships, foreigners, couples with children and for commercial purposes.

If a female sentenced to death is found to be pregnant, High Court shall commute the sentence to imprisonment for life as per Section 416 Criminal Procedure Code [2].

There have been instances reported wherein a female comes to know of her pregnancy only at the time of delivery. It is a known medical entity. Usually, a single ovum gets released in the middle of a menstrual cycle, which gets fertilized by sperm from a recent act of sexual intercourse. But it is possible that instead of a single ovum, two ova get released during the same cycle and get fertilized from two different acts of coitus, within a short time frame. This condition is known as 
superfecundation. Once pregnancy starts, ovum do not release in subsequent period. But it is possible that another ovum gets released following fertilization from earlier period and female gets pregnant on an already ongoing pregnancy. The babies delivered shall have different periods of gestation. This phenomenon is called as superfetation.

To prohibit sex selection of fetus, Pre-conception and Pre-natal diagnostic techniques Act is in force since 1994. It prohibits sex selection before conception as well as before delivery. If mother so desires, it is punishable with 3 year's imprisonment and Rs. 50,000/- fine on 1st instance while with 5 year's imprisonment and 1,00,000/- fine on 2 nd instance. If any woman is compelled, the compelling person is thus punishable.

With regards to medical termination of pregnancy desired by any female, her valid age of consent is 18 years with no age proof needed. If she is below 18 years, consent of parents or guardian is needed. Termination is allowed if there is threat to health of mother, threat to health of to be borne baby, if pregnancy is due to failure of contraception or as a result of sexual assault. Mere statement of female is acceptable with regards to her age, failure of contraception and allegation of sexual assault. Any such termination is to be done at a registered medical facility and by a competent medical practitioner as per the MTP Act 1971. MTP is allowed upto 20 weeks of pregnancy but can be done even after the said period, if the life of mother is in danger due to continued pregnancy [6]. Any act done against the provisions of MTP Act 1971 can be punished as per Sections 312 316 of Indian Penal Code.

In cases of alleged sexual assault, revealing the identity of victim is punishable under Section 228 A, IPC [1]. The Central Government has issued guidelines making provision for first aid and treatment of victims of sexual assault free of cost to be provided by all hospitals and immediate information to police.

Protection of Children from Sexual Offences Act 2012 [POCSO 2012] [7] provides that all cases of sexual assault, on boy or a girl, need to be mandatorily informed to police by anyone who comes to have information regarding it [this includes medical practitioners too]. As per the act, all females under 18 years of age are to be examined by female medical practitioners only. In case a female witness is not available during examination of a female victim of sexual assault, it is the duty of hospital owner to provide for the same for safe and secure medical examination of such victim.

Ministry of Health and Family Welfare, Government of India has issued Guidelines, in 2014 [8], where in cases of medical examination of a victim of alleged sexual assault, a copy of the medical report should be given free to victim; if age proof is available medical practitioner need not proceed with age estimation of the victim and apart from medical examination with regards to alleged sexual assault, all required treatment [emergency contraceptive, antibiotics, psychological counselling, HIV prophylaxis etc.] should be given to the victim.

\section{CONCLUSION}

There are numerous instances where a female comes in contact with a medical practitioner for an issue that has legal ramifications. With numerous instances and even more legal provisions, it has been observed that even the medical practitioners are most of the time not aware of these provisions and may not act according to it. In such a scenario, it is impractical to expect all females to be aware of their rights and responsibilities with regards to medicolegal issues. Even though efforts are being made on part of medical practitioners to educated women on such issues, whenever confronted with, larger measures still are need of the hour for widespread education on these issues.

\section{REFERENCES}

1. Ratanlal \& Dhirajlal. The Indian Penal Code 33rd ed. Lexis Nexis, Nagpur; 2011

2. The Code of Criminal Procedure [amendment] Act, 2005 [No. XXV of 2005] dated June 23, 2005.

3. Office of Health and Family Welfare. Government of Gujarat. GO HSP/ 1091/ 3663/ A; Secretariat, Gandhinagar: 4th February 1992 
4. The Delhi Artificial Insemination [Human] Act, 1995. Available at World Wide Web http://www.lawsofindia.org/pdf/delhi/1996/1996Delhi12.pdf

5. National Guidelines for Accreditation, Supervision and Regulation of ART Clinics in India. Indian Council of Medical Research \& National Academy of Medical Sciences, New Delhi 2005. Available at World Wide Web https://www.icmr.nic.in/guidelines?field_select_disease_tid=90

6. The Surrogacy (Regulation) Bill, 2018. Available at World Wide Web http://164.100.47.4/BillsTexts/LSBillTexts/PassedLoksabha/257-C\%20_2016_Eng..pdf

7. The Protection of Children from Sexual Offences Act, 2012. Available at World Wide Web https://wcd.nic.in/sites/default/files/childprotection31072012.pdf

8. Guidelines and protocols. Medico-legal care for survivors/ victims of sexual offence. Ministry of Health and Family Welfare, Government of India 2014. Available at World Wide Web https://mohfw.gov.in/sites/default/files/953522324.pdf

\section{Acknowledgements - Nil \\ Source of Funding - Nil \\ Conflict of Interest $-\mathrm{Nil}$}

